

Engineer Research and Development Center

\title{
High Efficiency Fuel Sleds for Polar Traverses
}

James $\mathrm{H}$. Lever and Jason C. Weale

March 2022 
The U.S. Army Engineer Research and Development Center (ERDC) solves the nation's toughest engineering and environmental challenges. ERDC develops innovative solutions in civil and military engineering, geospatial sciences, water resources, and environmental sciences for the Army, the Department of Defense, civilian agencies, and our nation's public good. Find out more at www.erdc.usace.army.mil.

To search for other technical reports published by ERDC, visit the ERDC online library at https://erdclibrary.on.worldcat.org/discovery. 


\section{High Efficiency Fuel Sleds for Polar Traverses}

James H. Lever and Jason C. Weale

Cold Regions Research and Engineering Laboratory

US Army Engineer Research and Development Center

72 Lyme Road

Hanover, NH 03755

Final report

Approved for public release; distribution is unlimited.

\footnotetext{
Prepared for National Science Foundation

Alexandria, VA 223

Under NSF Office of Polar Programs
} 


\section{Preface}

This study was conducted for the National Science Foundation, Office of Polar Programs (NSF-OPP). The research described and the resulting analyses presented were funded under NSF-OPP for the year-round research station at South Pole, Antarctica.

The work was performed by U.S. Army Engineer Research and Development Center, Cold Regions Research Engineering Laboratory (ERDCCRREL). At the time of publication of this paper, the deputy director for ERDC-CRREL was Mr. Bryan E. Baker and the director was Dr. Joseph Corriveau.

This paper was originally published online in the Journal of Terramechanics on 2 June 2012.

COL Teresa A. Schlosser was the commander of ERDC and the director was Dr. David W. Pittman.

DISCLAIMER: The contents of this report are not to be used for advertising, publication, or promotional purposes. Citation of trade names does not constitute an official endorsement or approval of the use of such commercial products. All product names and trademarks cited are the property of their respective owners. The findings of this report are not to be construed as an official Department of the Army position unless so designated by other authorized documents. 


\title{
High Efficiency Fuel Sleds for Polar Traverses
}

\begin{abstract}
We describe here the evolution of lightweight, high-efficiency fuel sleds for Polar over-snow traverses. These sleds consist of flexible bladders strapped to sheets of high molecular weight polyethylene. They cost 1/6th, weigh 1/10th and triple the fuel delivered per towing tractor compared with steel sleds. An eight-tractor fleet has conducted three $3400-\mathrm{km}$ roundtrips to South Pole with each traverse delivering $\sim 320,000 \mathrm{~kg}$ of fuel while emitting $<1 \%$ the pollutants, consuming $1 / 2$ the fuel and saving $\sim \$ 1.6 \mathrm{M}$ compared with aircraft resupply. A two-tractor fleet in Greenland recently delivered $\sim 83,000 \mathrm{~kg}$ of fuel in bladder sleds to Summit with similar benefits. Performance monitoring has revealed that bladder-sled towing resistance is largely governed by sliding friction, which can start high and drop in half over the first $30 \mathrm{~min}$ of travel. Frictional heating probably produces a thin water layer that lubricates the sled-snow interface. Consequently, towing resistance depends on the thermal budget of the sled. For example, black fuel bladders increase solar gain and thus decrease sled resistance; data suggest they could double again the fuel delivered per tractor. The outstanding efficiency and low cost of these sleds has transformed fuel delivery to Polar research stations.
\end{abstract}

\section{Introduction}

The National Science Foundation's Office of Polar Programs (NSF-OPP) operates year-round research stations at South Pole, Antarctica, and Summit, Greenland. Historically, all resupply operations for these stations were conducted using ski-equipped LC130 aircraft landing on prepared-snow runways. While effective, drawbacks of aircraft resupply include high fuel consumption and air emissions, payload weight and size limits, weather restrictions and high costs.

Beginning in 2003, NSF-OPP initiated an over-snow traverse to resupply South Pole Station from McMurdo Station, a one-way distance of $1660 \mathrm{~km}$. The intent was to use large rubber-tracked agricultural tractors to tow fuel and cargo sleds directly over natural snow. However, conventional steel sleds developed very high towing resis- tance and unacceptably large motions when towed inline with the tractors. These mobility problems threatened the very feasibility of over-snow resupply. Lever et al. [1] proposed expedient solutions including spacing skis outside of tractor ruts, increasing ski area and improving nose shapes. These solutions worked remarkably well $[2,3]$ and established a key principle: over-snow traverses must achieve high transport efficiency to become an acceptable alternative to aircraft operations.

To this end, NSF-OPP initiated a cycle of innovation, laboratory tests, field validation, and refinement to improve the efficiency of its sleds. Because diesel fuel constitutes about half the cargo delivered to South Pole and Summit stations, initial development focused on fuel sleds. By 2008, this effort showed sufficient promise to initiate a traverse to resupply Summit Station from Thule, Greenland, $1170 \mathrm{~km}$ one-way [4,5].

We describe here the evolution and performance of high-efficiency fuel sleds now used for Antarctic and Greenland traverses. These sleds consist of flexible fuel bladders strapped to sheets of flexible plastic (Fig. 1). 


\section{Nomenclature}

$D B P \quad$ drawbar pull $(\mathrm{kN})$

$k \quad$ snow indentation strength $(\mathrm{kPa} / \mathrm{m})$

$\mu \quad$ sliding friction coefficient

$p(z) \quad$ indentation pressure $(\mathrm{kPa})$

$p_{0} \quad$ average contact pressure $(\mathrm{kPa})$

$R \quad$ average sled resistance $(\mathrm{kN})$

$R_{c} \quad$ snow-compaction resistance $(\mathrm{kN})$

$\sigma_{R} \quad$ standard deviation of sled resistance $(\mathrm{kN})$
$T \quad$ total sled resistance, $T=R+3 \sigma_{R}(\mathrm{kN})$

$T_{s p} \quad$ spatial-average sled-snow interface temperature $\left({ }^{\circ} \mathrm{C}\right)$

$W \quad$ total weight $(\mathrm{kN})$

$W_{p} \quad$ payload weight $(\mathrm{kN})$

$W_{t} \quad$ tare weight $(\mathrm{kN})$

$z \quad$ indentation depth or sinkage (m)

$z_{m} \quad$ maximum sinkage $(\mathrm{m})$
By virtue of their low towing resistance, tare weight and cost, these sleds have transformed fuel delivery to US Polar research stations.

\section{Design approach and performance monitoring}

The primary South Pole Traverse (SPoT) towing tractors are Case STX530 Quadtracs and AGCO MT865s. The Greenland Inland Traverse (GrIT) uses Case STX485 Quadtracs. These tractors are commercial models fitted with cold-weather packages and optionally wider tracks. They perform quite well over natural Polar snow.

Table 1 summarizes the mobility characteristics of these tractors. Drawbar pull (DBP) values are average test and en-route values. Note the lower drawbar coefficients measured in Greenland reflect weaker surface snow compared with Antarctica [5,6].

There is relatively little latitude to modify these tractors. Increasing tractor weight does increase drawbar pull but also increases sinkage and risk of immobilization in soft snow. Consequently, available drawbar pull limits permissible sled-train resistance, and tractor power limits towing speeds. Our objective in sled design is thus to maximize towed payload within these limits.

Towing resistance of a sled consists of three main components: sliding friction, snow-compaction resistance and plowing resistance [1]. Plowing resistance can be extremely high and must be avoided through good design: ski noses with shallow entry angles and sinkage less than undercarriage clearance. Reducing sinkage also reduces snow-compaction resistance, $R_{c}$.

For a sled or ski with sinkage varying linearly from zero at the front to $z_{m}$ at the rear, we may use Bekker mobility theory [7-9] to obtain

$R_{c} / W=z_{m} / L$

where $W$ is sled weight and $L$ is sled or ski contact length. Indentation pressure, $p(z)$, in deep snow varies nearly linearly with penetration depth, $z$, so that [9]

$p(z)=k z$

and

$z_{m}=2 p_{0} / k$ where $k$ is indentation strength and $p_{0}$ is average contact pressure. Omitting plowing resistance but including friction coefficient $\mu$, dimensionless sled resistance becomes

$R / W=\mu+R_{c} / W=\mu+2 p_{0} / k L$

We may break out the components of sled weight as tare and payload weight, $W_{t}$ and $W_{p}$, respectively, to develop an equation to guide sled design:

$R=\left(W_{t}+W_{p}\right)\left(\mu+2 p_{0} / k L\right)$

Eq. (5) suggests that to minimize towing resistance for a given payload, we should

- Minimize tare weight.

- Minimize sliding friction.

- Minimize contact pressure.

- Maximize sled length.

Here $R$ is average towing resistance over some region or time interval. Actually, snow strength and surface roughness vary over scales comparable to sled-train lengths [1]. To avoid frequent immobilizations on resistance peaks, we normally include resistance variations when assessing total resistance:

$T=R+3 \sigma_{R}$

Thus, minimizing sensitivity to strength and roughness variations is also important.

The physics describing sliding friction of skis over snow has received considerable attention [10-12]. Similar physics applies to large sleds. On snow colder than about $-5^{\circ} \mathrm{C}$, dry snow grains produce high startup friction $(\mu \sim 0.2-$ 0.3 ). As the sled slides, frictional heating warms the snow-grain contact points and produces local melting. The sled also warms up in response. The resulting thin melt-water layer lubricates the sled-snow interface and reduces friction. The longer the sled, the longer the contact time for frictional heating and the lower the local interface friction. This process can produce too much melt water and increase friction (via suction) when snow temperature exceeds about $-5^{\circ} \mathrm{C}$, but for most polar conditions warmer sleds will slide easier than colder ones. Thus, design choices that increase the sled-snow interface temperature, 


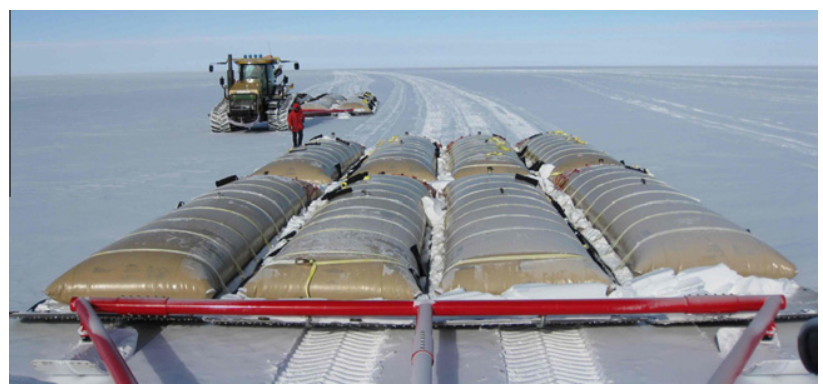

Fig. 1. Groups of eight 11,400-L fuel bladders on flexible sleds towed behind tractors during 2009-10 South Pole Traverse.

Table 1

Mobility characteristics of traverse tractors. $D B P$ are average values $( \pm 10 \%)$.

\begin{tabular}{llllll}
\hline Tractor & Mass $(\mathrm{kg})$ & Power $(\mathrm{kW})$ & $p_{0}(\mathrm{kPa})$ & $D B P(\mathrm{kN})$ & $D B P / W$ \\
\hline STX530 & 31,000 & 400 & 54 & 120 & 0.39 \\
MT865 & 25,000 & 400 & 43 & 110 & 0.46 \\
STX485 & 32,000 & 360 & 45 & 100 & 0.32 \\
STX485 $^{\text {a }}$ & 26,000 & 360 & 37 & 80 & 0.32 \\
\hline
\end{tabular}

${ }^{\text {a }} D B P$ value is an estimate based on the measured performance of the heavier STX485 in Greenland.

for example via solar gain on black surfaces, can reduce sliding friction.

We have been documenting the performance of the SPoT and GrIT traverse fleets since their inceptions [1-6]. Our instrumentation package now includes a custom-made $220 \mathrm{kN}$ load pin to measure towing force directly at the drawbar hitch (Fig. 2), a GPS receiver for tractor position, speed and altitude, and a datalogger to record these values. We normally sample at $1 \mathrm{~Hz}$ and record towing resistance and speed as 10-s to 1-min averages and standard deviations. For drawbar-pull tests, we increase sample rate to $5 \mathrm{~Hz}$.

Typical travel speeds for both SPoT and GrIT are 8$11 \mathrm{~km} / \mathrm{h}$. Both traverse routes climb from sea level to $\sim 3300 \mathrm{~m}$ maximum elevation and encounter $\sim 0.08$ maximum slopes. Snow strengths in the top $1 \mathrm{~m}$, as measured via Rammsonde penetrometer, are generally lower in Greenland compared with Antarctica [5,6], although a region along the Antarctic Plateau has both soft snow and cold temperatures that significantly restricts SPoT

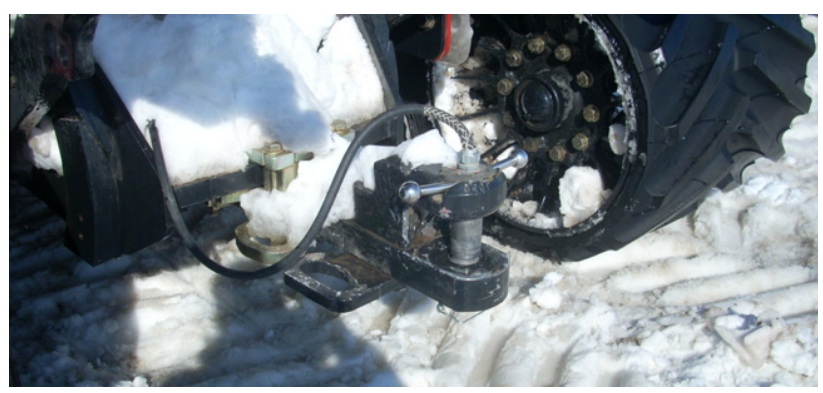

Fig. 2. Custom-made load pin to measure towing forces at drawbar hitch. mobility. Tractor sinkage is generally higher in Greenland, $20-40 \mathrm{~cm}$ versus $10-20 \mathrm{~cm}$ in Antarctica.

\section{Steel versus flexible fuel sleds}

Steel fuel sleds have design constraints that contribute to high towing resistance. The structural objective is to carry fuel in a rigid container and distribute that weight over large skis to minimize contact pressure. The skis must be strong enough to prevent buckling as they support the sled over rough snow. These structural requirements add tare weight and cost to steel sleds and limit the practical width and length of skis. Furthermore, over rough or varyingstrength snow, only a portion of the ski may support sled weight. This increases local contact pressure and thus snow-compaction resistance. And despite having polyethylene runners, steel skis generate high sliding friction via limited contact length and high heat conduction away from the snow interface.

By comparison, bladder sleds use very lightweight materials: fabric-reinforced polyurethane fuel bladders strapped to extruded sheets of $1.3-\mathrm{cm}$-thick high molecular weight polyethylene (HMW-PE). Tare weight is $\sim 1 / 10$ th that of a steel sled of the same capacity $(11,400 \mathrm{~L})$. Fuel weight is distributed over a large contact area $(\sim 2-\mathrm{m}$ wide $\times 8-\mathrm{m}$ long) to reduce contact pressure, and the flexible materials allow the sled to conform to rough snow surfaces. Consequently, bladder sleds produce negligible rut depths, hence negligible $R_{c}$, over essentially all snow conditions encountered on both traverse routes. Additionally, sleds with two bladders inline develop low friction owing to long sled-snow contact times. Remarkably, bladder sleds are also cheaper, costing $\sim \$ 15,000$ per 11,400 -L capacity versus $\sim \$ 100,000$ for a steel tank sled.

Fig. 3 shows a sled train of four 11,400-L steel fuel sleds towed on firm snow during SPoT05-06. This $2 \times 2$ arrangement keeps skis on firm snow outside tractor ruts and thus reduces towing resistance [1-3]. Nevertheless, across most of the SPoT route, four steel sleds have towing resistance comparable to eight tan-colored bladder sleds (Fig. 1). Because the fleet consumes the fuel in two of these sleds during a round-trip to South Pole, bladder sleds essentially

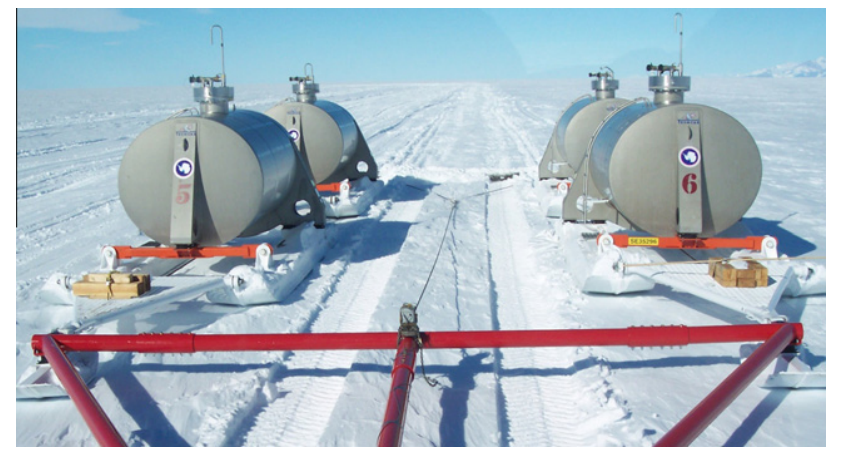

Fig. 3. Sled train consisting of four 11,400-L steel fuel sleds towed outside of tractor ruts via red spreader. 
Table 2

Characteristics and performance measures for 11,400-L fuel sleds. Values for bladder sleds are per bladder for two bladders inline on the same HMW-PE sled. The ranges for towing resistance reflect regional variations in snow strength and temperature (see text).

\begin{tabular}{llll}
\hline Parameter & $\begin{array}{l}\text { Steel } \\
\text { tank }\end{array}$ & $\begin{array}{l}\text { Tan } \\
\text { bladders }\end{array}$ & Black bladders \\
\hline Tare, $W_{t}(\mathrm{~kg})$ & 5600 & 500 & \\
Total, $W(\mathrm{~kg})$ & 15,200 & 10,000 & \\
Payload fraction, $W_{p} / W$ & 0.63 & 0.95 & \\
Contact pressure, $p_{0}(\mathrm{kPa})$ & 13.2 & 6.4 & \\
Average resistance, $R / W$ & $0.07-0.5$ & $0.04-0.09$ & $0.03-0.05$ \\
Total resistance, $T / W$ & $0.1-0.6$ & $0.05-0.12$ & $0.04-0.07$ \\
Payload efficiency, $W_{p} / T$ & $1-6$ & $8-19$ & $14-23$ \\
S. Pole delivery per tractor $(\mathrm{L})$ & 23,000 & 68,000 & $114,000-160,000$ \\
\hline
\end{tabular}

triple fuel delivery per tractor from $23,000 \mathrm{~L}$ to $68,000 \mathrm{~L}$. Table 2 summarizes performance measures for steel and flexible fuel sleds.

Snow-compaction and sliding friction are both important sources of towing resistance for steel sleds. Because sinkage depends on snow strength, $R_{c}$ for steel sleds increases dramatically in soft snow, and sinkage greater than $\sim 25 \mathrm{~cm}$ will cause tank saddles to plow. As noted, steel skis also increase sliding friction. On firm Antarctic snow in mild temperatures, towing resistance of steel sleds can be $T / W \sim 0.10-0.12$, but we have measured $T / W \sim$ 0.3-0.6 over most of the GrIT route and on the Antarctic Plateau. Resistance variations can also be large owing to strength variations and pitching motions over rough snow.

By comparison, bladder sleds achieve much lower resistance per unit weight and are less sensitive to snow strength, with $T / W \sim 0.04-0.12$ across all conditions encountered to date. Combined with their higher payload fraction, the payload efficiency (payload weight per unit towing force) is much higher, $W_{p} / T \sim 8-23$ versus $1-6$ for steel tanks.

An initial concern was whether towing fuel in flexible sleds over rough snow would cause bladders to rupture. To address this, in 2008 we cycled an 11,400-L bladder sled over a $1.5-\mathrm{m}$-high snow bump in a large cold room at CRREL (Fig. 4). Air temperature was $-29^{\circ} \mathrm{C}$ and travel speeds mimicked traverse speeds, although acceleration/ deceleration at each end of the test run was more severe

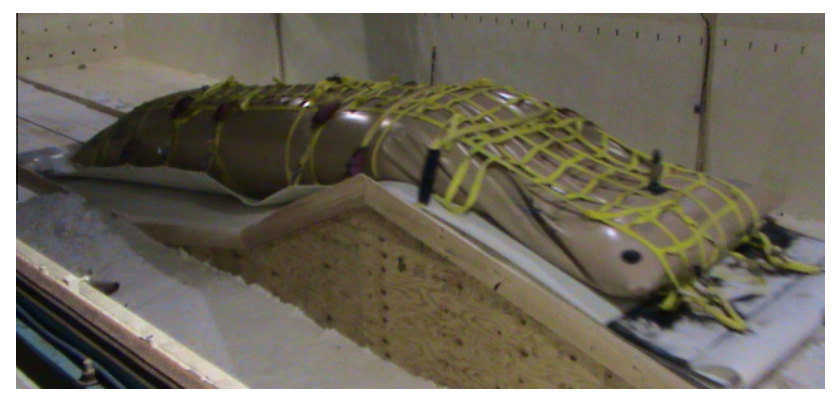

Fig. 4. Full-scale 11,400-L bladder sled filled with kerosene undergoing durability tests at $-29^{\circ} \mathrm{C}$. Bladder did not rupture despite severe flexing and folding of material and sloshing of fuel. than in-service conditions. No ruptures occurred, and the bladder successfully completed 3860 round-trip cycles before developing a minor leak. This represents $\sim 15$ trips across the region of large sastrugi encountered en-route to South Pole. Both SPoT and GrIT put bladder sleds into large-scale service following these tests.

\section{Sliding friction and sled temperature}

During SPoT08-09, we measured towing forces during startup on cold days $\left(<-20^{\circ} \mathrm{C}\right)$ that were double the eventual steady state resistance for groups of 8-12 tan fuel bladders. These startup values could cause tractors to break traction during the 10-30 min needed for the sleds to "warm up." Frictional heating amounted to $\sim 1-3 \mathrm{~kW} / \mathrm{m}^{2}$ of contact area during this period. Stops for lunch or other breaks could recreate this transient behavior (with slightly shorter warm-up periods). In fact, high startup resistance on the cold Antarctic Plateau limits SPoT's practical towing capacity and hence deliverable payload. For SPoT0910 , we installed thermocouples along the length of one dual-bladder sled, at the interface with the snow surface, to link sled temperature with towing resistance (Fig. 5). We also measured bladder fuel temperature, solar irradiance and air temperature.

Fig. 6 shows towing resistance, $R / W$, and spatial-average sled-snow interface temperature, $T_{s p}$, during a test in Antarctica. Air temperature was $-30{ }^{\circ} \mathrm{C}$. Startup resistance after a 20 min stop was close to the drawbar limit of the tractor and decreased over the next 30 min to nearly half that value as sled-snow interface temperature increased $\sim 7^{\circ} \mathrm{C}$. These results confirmed the important role of the thermal budget (frictional heating, solar gain, heat conduction into snow and bladder, etc.) on towing resistance of the bladder sleds. They also suggested that we could reduce towing resistance by warming the sled-snow interface via variations in sled design.

For GrIT10, we instrumented two dual-bladder sleds with thermocouples and separate load pins. One sled had electric heating blankets $\left(300 \mathrm{~W} / \mathrm{m}^{2}\right)$ under tan bladders.

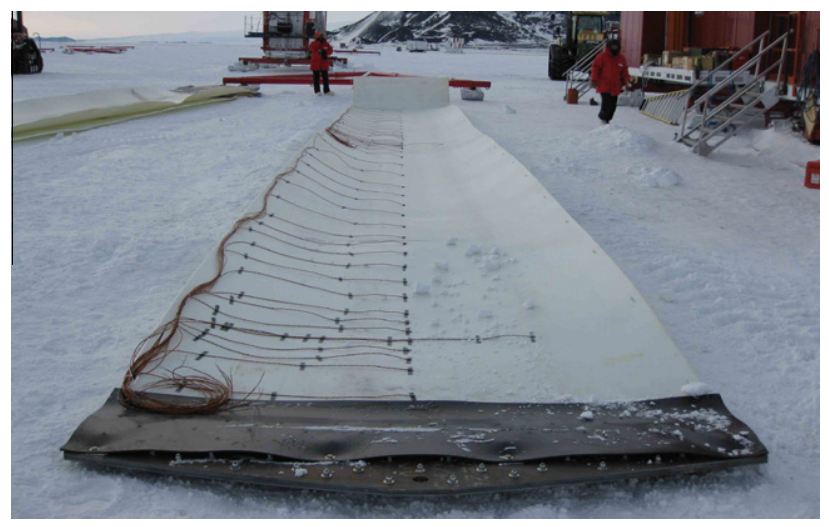

Fig. 5. Thermocouples (46 total) installed along the length of a bladder sled to measure sled-snow interface temperature. Thermocouple junctions were flush with the bottom of the sled. 




Fig. 6. Start-up transient of towing resistance and spatial-average sledsnow interface temperature for eight tan bladders during tests in Antarctica (10-s averages of $1 \mathrm{~Hz}$ data).

The blankets were insulated on top to heat the HMW-PE sheet preferentially. We obtained data with the heaters on and off (insulation only). The other sled had thin black covers wrapping the bladders to increase solar gain (black bladders were not yet available). Fig. 7 correlates $R / W$ with $T_{s p}$ under steady state towing conditions for all data obtained during GrIT10. Because $R_{c}$ is small for bladder sleds, $R / W$ is equivalent to friction coefficient $\mu$ (Eq. (5)).

Sled-snow interface temperature collapsed towing resistance of the GrIT10 bladder sleds regardless of sled design (Fig. 7). Resistance dropped with increasing $T_{s p}$ until $\sim-5^{\circ} \mathrm{C}$. Warmer temperatures produced constant or slightly increased resistance. These results are consistent with theory for ski-snow sliding friction [10-12].

For SPoT10-11, we obtained and instrumented sleds consisting of eight black bladders (Fig. 8). We expected black bladders to be more efficient than black covers to capture solar energy during the generally clear, 24-h daylight conditions characteristic of Polar summers.

We may compare bladder-sled resistance data from several seasons in Antarctica and Greenland using air temper-

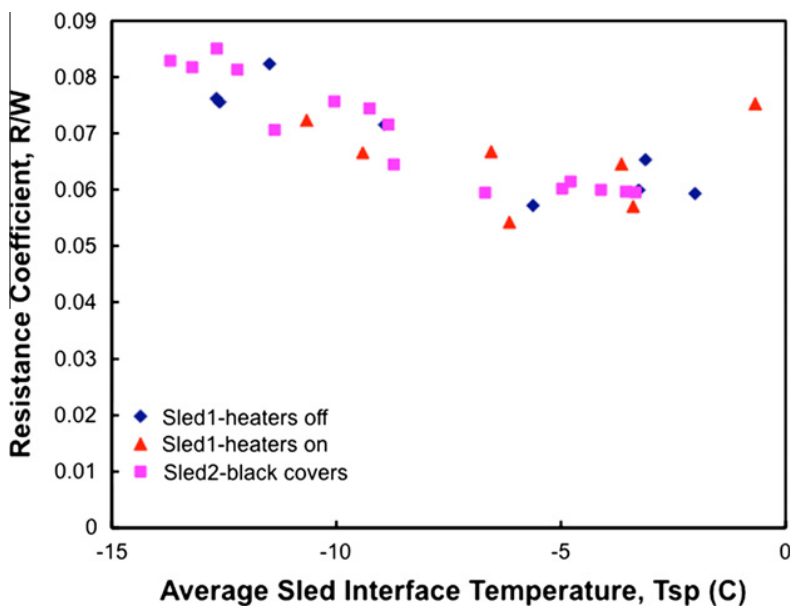

Fig. 7. $R / W$ versus $T_{s p}$ for bladder sleds during GrIT10. Sled 1 had heating blankets under the bladders; Sled 2 had black covers wrapped around the bladders.

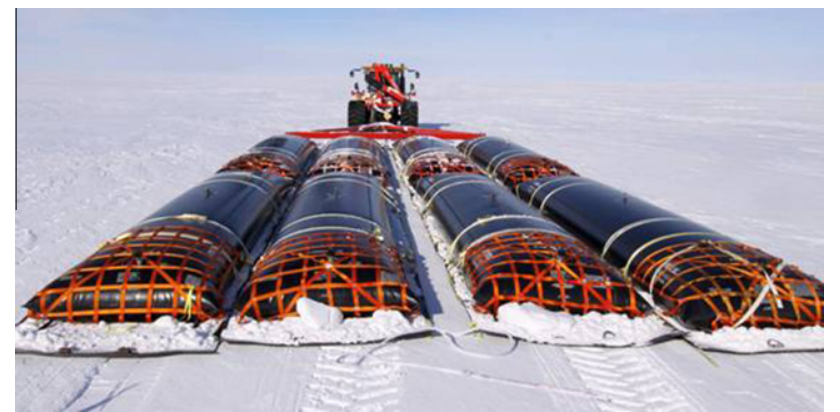

Fig. 8. Eight black fuel bladders towed in Antarctica during SPoT10-11.

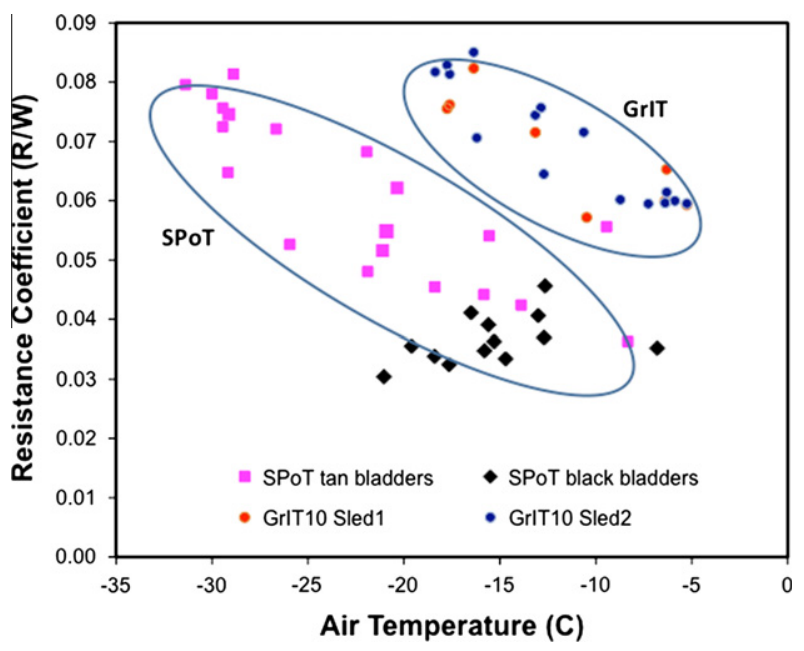

Fig. 9. Resistance versus air temperature for SPoT and GrIT unheated bladder sleds. Note the large reduction in resistance possible with black bladders.

ature as a surrogate for $T_{s p}$. Fig. 9 shows the result. The data are more scattered than in Fig. 7 because several heat-transfer processes influence sled interface temperatures, but they are nevertheless quite useful.

The unheated GrIT sleds plot as a group, showing a similar trend of decreasing resistance with temperature as when plotted using $T_{s p}$. The SPoT tan bladders also show this trend but plot beneath the GrIT data. That is, for similar air temperatures, the tan-bladder sleds in Antarctica tow easier than those in Greenland. Fortunately for GrIT, air temperatures are generally warmer in Greenland, so mobility-limiting towing resistance is similar.

The most notable result from Fig. 9 is the low resistance of sleds using black bladders. Solar heating of the fuel accounts for this difference. During head-head tests in Antarctica at $-21^{\circ} \mathrm{C}$ under clear skies, fuel in black bladders was $4{ }^{\circ} \mathrm{C}$ warmer than that in tan bladders and $11^{\circ} \mathrm{C}$ warmer than ambient. Towing resistance was $40 \%$ lower, and each SPoT tractor could tow 16 fuel bladders under these conditions. Although data are needed at lower air temperatures, black bladders could double fuel delivery to South Pole compared with the already efficient tan bladders (Table 2). 


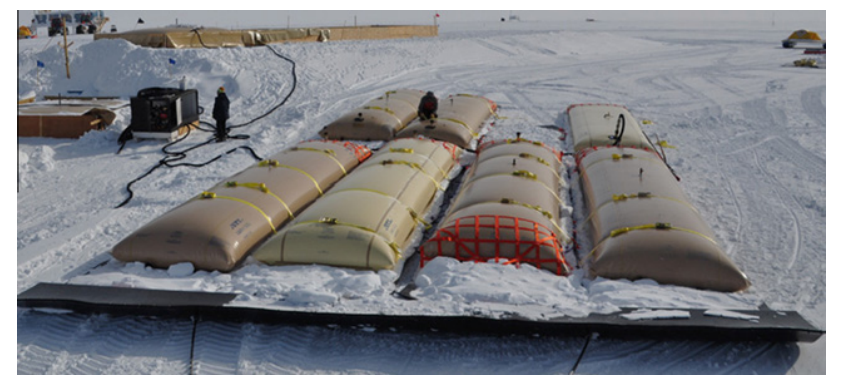

Fig. 10. Off-loading fuel delivered by one GrIT11 tractor to Summit Station, Greenland.

\section{Discussion and conclusions}

Mobility performance lies at the heart of Polar traverses. The Antarctic and Greenland fleets are towing heavy cargo directly across natural snow. Frequent immobilizations limit daily progress, disrupt schedules, abuse equipment and stress crews. This puts pressure to reduce weight towed per tractor and thus reduce delivered payload. However, the fleet must maximize delivered payload to justify its capital and operating costs. With the support of NSF and traverse managers, we have advanced the efficiency of fuel sleds to satisfy these demands.

Flexible fuel-bladder sleds have inherent advantages over conventional steel sleds: low and uniform contact pressure, longer length, lower tare weight and lower cost. Their higher payload efficiency (payload weight per unit towing force) triples the fuel delivery possible per SPoT tractor compared with steel sleds.

High-efficiency bladder sleds enhance traverse versus aircraft resupply of Polar research stations. SPoT's eight-tractor fleet has conducted three $3400-\mathrm{km}$ roundtrips to South Pole (2008-11) with each traverse delivering $\sim 320,000 \mathrm{~kg}$ of fuel on bladder sleds while emitting $<1 \%$ the pollutants and consuming $1 / 2$ the fuel compared with LC130 delivery. We have begun a formal study of the economic benefits of SPoT, but annual deliveries offset $\sim 32$ LC130 flights, directly saving $\sim \$ 1.6 \mathrm{M}$ in aircraft and fuel costs.

GrIT has recently completed its first operational traverse to Summit Station, with two tractors delivering $\sim 83,000 \mathrm{~kg}$ of fuel in bladder sleds (Fig. 10). Because much of the scientific research conducted in Greenland relies on clean air and snow sampling, large emissions reductions by traverse resupply make it more attractive than cost savings alone $[3,4]$.

Sliding friction dominates the towing resistance of bladder sleds, and as with skis, temperature of the sled-snow interface plays a key role. For most Polar conditions, warmer sleds will slide easier than colder ones. Thus, design options that increase sled temperatures become attractive. For simplicity, we prefer passive solar gain to active heating of the sled. Indeed, black bladders could double again the fuel delivered per tractor to South Pole with essentially no attendant cost increase.

Clearly, towing resistance of a bladder sled is not a single value. We must account for regional and seasonal temperature variations (Fig. 9). Fleet-limiting mobility conditions exist when cold temperatures (high sled resistance) combine with soft snow (low tractor drawbar pull). Unfortunately, these conditions exist across the Antarctic Plateau and much of the Greenland ice cap. Nevertheless, black bladders should improve mobility across these areas, which also tend to have clear skies during Polar summers.

Interestingly, the data in Fig. 9 indicate that (tan) bladders sleds have higher resistance in Greenland than in Antarctica at the same air temperatures. We believe that snow strength plays a role, though not through snow-compaction resistance. Production of a lubricating water layer at the sled-snow interface depends on the actual contact area of the supporting snow grains [11]. Weaker snow requires more contact area to support the sled, which would spread frictional heating over larger areas to reduce interface temperature and water-layer thickness. We are attempting to model the physics of sled-snow friction to assess this versus other explanations and to guide further sled improvements.

Snow-compaction resistance cannot solely account for the high towing resistance of steel fuel sleds. Maximum sinkage before saddles drag (an uncommon occurrence) is $\sim 30 \mathrm{~cm}$. For 6.2-m-long steel skis, Eq. (1) suggests $R_{c} /$ $W<0.05$, much less than measured values (Table 2). High sliding friction owing to cold interface temperatures is the likely explanation. Black paint or active heaters might offer benefits, but these are unlikely to overcome other disadvantages of steel sleds (high tare weight, contact pressure and cost).

The primary drawback of bladder sleds is their durability relative to steel sleds. The bladders themselves have performed well, and few leaks have developed during service. However, numerous HMW-PE sheets have broken during SPoT, necessitating in-field fuel transfers and sled replacement. We have identified reduced ductility at low temperatures/high loading rates as the likely cause and are working with vendors to encourage production of HMW-PE sheets tailored to our service needs. This problem reflects the recent introduction of flexible-sled technology, and we expect it to resolve it soon.

Flexible fuel-bladder sleds are now in service in large numbers on over-snow traverses in Antarctica and Greenland. They enable these traverses to offset aircraft resupply flights with large fuel, emissions and cost benefits. While sled durability still needs improvement, the outstanding efficiency and low cost of these sleds has transformed fuel delivery to US Polar research stations.

\section{Acknowledgements}

The authors gratefully acknowledge the commitment of NSF Program managers George Blaisdell and Pat Haggerty to advance Polar sled technology, and the support of traverse managers Paul Thur, Jay Burnside, Brad Johnson and Terry Billings to help us implement and test these new sleds across Antarctica and Greenland. 


\section{References}

[1] Lever JH, Weale JC, Alger RG, Blaisdell GL. Mobility of cargo trains during year two of the proof-of-concept South Pole traverse. ERDC/ CRREL technical report TR-04-22. Cold Regions Research and Engineering Laboratory, Hanover, NH; 2004.

[2] Lever JH, Weale JC, Alger RG, Blaisdell GL, Wright JH. Mobility solutions for the South Pole traverse tractor-sled trains. In: 10th European conference of ISTVS, Budapest, Hungary; 2006.

[3] Weale J, Lever JH. Innovations in over-snow cargo transport. Cold Reg Sci Technol 2008;52:166-76.

[4] Lever JH, Weale JC. Feasibility of overland traverse to re-supply Summit camp: fleet configuration and economic analysis. ERDC/ CRREL TR-11-7. Cold Regions Research and Engineering Laboratory, Hanover, NH; 2011.

[5] Lever JH, Weale JC. Mobility and economic feasibility of the Greenland inland traverse (GrIT). ERDC/CRREL TR-11-9. Cold Regions Research and Engineering Laboratory, Hanover, NH; 2011.
[6] Lever JH. Greenland inland traverse (GrIT): 2010 mobility performance and implications. ERDC/CRREL TR-11-16. Cold Regions Research and Engineering Laboratory, Hanover, NH; 2011.

[7] Bekker MG. Theory of land locomotion - the mechanics of vehicle mobility. Ann Arbor, (Michigan): University of Michigan Press; 1956.

[8] Wong JY. Terramechanics and off-road vehicles. Amsterdam: Elsevier; 1989.

[9] Lever JH, Denton D, Phetteplace GE, Wood SD, Shoop SA. Mobility of a lightweight tracked robot over deep snow. J Terramech 2006;43:527-51.

[10] Colbeck SC. A review of the processes that control snow friction. CRREL report 92-2. Cold Regions Research and Engineering Laboratory, Hanover, NH; 1992.

[11] Bäurle L, Kaempfer U, Szabó D, Spencer ND. Sliding friction of polyethylene on snow and ice. Contact area and modeling. Cold Reg Sci Technol 2007;47:276-89.

[12] Colbeck SC, Perovich DK. Temperature effects of black versus white polyethylene bases for snow skis. Cold Reg Sci Technol 2004;39:33-8. 


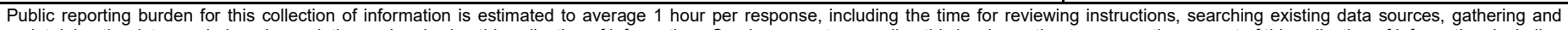





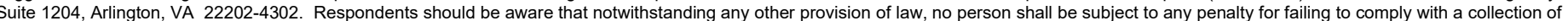
information if it does not display a currently valid OMB control number. PLEASE DO NOT RETURN YOUR FORM TO THE ABOVE ADDRESS.

\section{REPORT DATE March 2022 \\ 2. REPORT TYPE \\ Final}

4. TITLE AND SUBTITLE

High Efficiency Fuel Sleds for Polar Traverses

3. DATES COVERED (From - To)

5a. CONTRACT NUMBER

5b. GRANT NUMBER

5c. PROGRAM ELEMENT NUMBER

\section{5d. PROJECT NUMBER}

James H. Lever and Jason C. Weale

5e. TASK NUMBER

5f. WORK UNIT NUMBER

8. PERFORMING ORGANIZATION REPORT NUMBER

ERDC/CRREL MP-22-8

Cold Regions Research and Engineering Laboratory

U.S. Army Engineer Research and Development Center

72 Lyme Road

Hanover, NH 03755

9. SPONSORING / MONITORING AGENCY NAME(S) AND ADDRESS(ES)

National Science Foundation

Alexandria, VA 22314

10. SPONSOR/MONITOR'S ACRONYM(S) NSF

11. SPONSOR/MONITOR'S REPORT NUMBER(S)

\section{DISTRIBUTION / AVAILABILITY STATEMENT}

Approved for public release; distribution is unlimited.

\section{SUPPLEMENTARY NOTES}

This paper was originally published online in the Journal of Terramechanics on 2 June 2012.

\section{ABSTRACT}

We describe here the evolution of lightweight, high-efficiency fuel sleds for Polar over-snow traverses. These sleds consist of flexible bladders strapped to sheets of high molecular weight polyethylene. They cost 1/6th, weigh 1/10th and triple the fuel delivered per towing tractor compared with steel sleds. An eight-tractor fleet has conducted three 3400-km roundtrips to South Pole with each travers delivering $320,000 \mathrm{~kg}$ of fuel while emitting $<1 \%$ the pollutants, consuming $1 / 2$ the fuel and saving $\$ 1.6$ $\mathrm{M}$ compared with aircraft resupply. A two-tractor fleet in Greenland recently delivered 83,000 $\mathrm{kg}$ of fuel in bladder sleds to Summit with similar benefits. Performance monitoring has revealed that bladder-sled towing resistance is largely governed by sliding friction, which can start high and drop in half over the first 30 min of travel. Frictional heating probably produces a thin water layer that lubricates the sled-snow interface. Consequently, towing resistance depends on the thermal budget of the sled. For example, black fuel bladders increase solar gain and thus decrease sled resistance; data suggest they could double again the fuel delivered per tractor. The outstanding efficiency and low cost of these sleds has transformed fuel delivery to Polar research stations.

\section{SUBJECT TERMS}

Over-snow mobility; Sliding friction; Transport efficiency; Polar resupply operations

\begin{tabular}{|l|c|c|c|c|l|}
\hline \multicolumn{2}{|l|}{ 16. SECURITY CLASSIFICATION OF: } & $\begin{array}{c}\text { 17. LIMITATION } \\
\text { OF ABSTRACT }\end{array}$ & $\begin{array}{l}\text { 18. NUMBER } \\
\text { OF PAGES }\end{array}$ & $\begin{array}{l}\text { 19a. NAME OF RESPONSIBLE } \\
\text { PERSON }\end{array}$ \\
\cline { 1 - 2 } $\begin{array}{c}\text { a. REPORT } \\
\text { Unclassified }\end{array}$ & $\begin{array}{c}\text { b. ABSTRACT } \\
\text { Unclassified }\end{array}$ & $\begin{array}{c}\text { c. THIS PAGE } \\
\text { Unclassified }\end{array}$ & UU & 12 & $\begin{array}{l}\text { 19b. TELEPHONE NUMBER (include } \\
\text { area code) }\end{array}$ \\
\hline
\end{tabular}

